\title{
Vocational Education and Employment over the Life Cycle
}

\author{
Andrea G. Forster, Thijs Bol, Herman G. van de Werfhorst \\ University of Amsterdam
}

Abstract: Vocationally educated individuals often find employment sooner after school than those with a general educational qualification. A recent study has argued that the higher employment probability associated with a vocational qualification reverses in later life. The main explanation is that although having (occupation-)specific skills is an advantage when entering the labor market, specific skills also make the vocationally educated less flexible. This life cycle effect is hypothesized to be especially strong in countries where the vocational system provides highly occupation-specific skills. We test these two hypotheses on cross-national data from PIAAC 2012. Using logistic regressions with country fixed effects, we find that individuals with a vocational qualification have a higher employment probability than those with a general qualification at the start of their career, but this pattern reverses in later life. In contrast to earlier findings, we do not find that this effect varies systematically across countries with different vocational educational systems.

Keywords: vocational education; life cycle; educational system; labour market; PIAAC

Citation: Forster, Andrea G., Thijs Bol, and Herman G. van de Werfhorst. 2016. "Vocational Education and Employment over the Life Cycle" Sociological Science 3: 473-494.

Received: December 3, 2015

Accepted: February 15, 2016

Published: June 24, 2016

Editor(s): Jesper Sørensen, Stephen Morgan

DOI: $10.15195 / \mathrm{v3} . \mathrm{a} 21$

Copyright: (C) 2016 The Author(s). This open-access article has been published under a Creative Commons Attribution License, which allows unrestricted use, distribution and reproduction, in any form, as long as the original author and source have been credited. (0)(1)
$W^{\text {HEN rising youth unemployment sparks discussions about the problematic }}$ transition from school to work for many young school leavers, vocational education is often mentioned as a solution by policy makers (Hoffman 2011; OECD and ILO 2014; Biavaschi et al. 2013). At the same time, critics argue that vocational education is not compatible with a flexible labor market in which workers adapt easily to changing job content primarily caused by technological innovations.

Existing studies almost unambiguously find that vocationally trained students have a smoother transition to the labor market, for example, by obtaining a job faster than students with a general qualification (Arum and Shavit 1995; Shavit and Müller 1998; Müller and Gangl 2003; Breen 2005). The main explanation for this effect is that the occupation-specific skills that these students have obtained make them more attractive to employers. The benefits of a vocational qualification are highest when vocational education takes a prominent position in the educational system of a country, most clearly in the form of a dual system where school and work are combined (Wolbers 2007; Iannelli and Raffe 2007).

In a recent and influential study, Hanushek et al. (2016) argue that being vocationally educated might be a benefit at the start of a career but turns into a disadvantage later in life. Vocationally trained students have a higher probability of employment than those with a general educational qualification when they enter the labor market, but this pattern reverses around the age of 50. Both effects-early advantage and late disadvantage-seem to be due to the specific skills gained in vocational education, which smoothen the transition to a first job, but also make workers inflexible. Major technological innovations changed the skills that are re- 
quired in contemporary labor markets, making the specific skill set of vocationally trained workers inadequate for changing job content (Krueger and Kumar 2004a,b). Moreover, Hanushek et al. (2016) argue that the late-life penalty for vocationally trained workers is most prominent in countries with a strong occupation-specific dual training system, such as Germany or Austria, in contrast to countries where vocational educational programs are less institutionalized and of a more general nature (e.g., United States and England).

However, the empirical support for these hypotheses is limited and tested with data that make it difficult to identify those with a vocational qualification (Hanushek et al. 2016). Following a recent call for further research on school-to-work linkages in an influential report published at the WT Grant Foundation (Rosenbaum et al. 2015), we revisit these two proposed hypotheses: (1) vocationally educated individuals are more likely to be employed in the earlier career than those with a general education, but this pattern reverses in later life, and (2) this pattern is particularly strong in countries with a strong occupation-specific vocational education system.

We make three contributions. First, we theoretically and empirically disentangle the two levels at which Hanushek et al. (2016) formulate their expectations: the individual-level outcomes of having a vocational qualification and the moderating effect of the educational system of the country in which the individual obtained his or her degree. Second, in contrast to earlier studies, we estimate in a more formal way whether the effect of vocational education over the life cycle varies systematically across educational systems. Third, the data that are used for our study have a much higher quality for testing the life cycle effects of vocational education in a cross-national comparative design, as they allow us to include better controls for potential confounders such as competency and parental education.

Using data from the Programme of International Assessment of Adult Competencies (PIAAC 2012) for 22 OECD countries, we test our hypotheses in logistic regression models with country fixed effects, predicting the probability of being employed. We start our analyses with a pooled model to study the overall average life cycle effects of vocational education on employment. In a second step, we introduce country-level indicators for the vocational orientation of the educational system and test if there is systematic variation across countries. Finally, we take a closer look at the life cycle effects of vocational education in the single countries by conducting separate analyses for each country.

To foreshadow our results, we find that vocationally trained workers experience an initial advantage and later-life disadvantage in their employment probabilities. Although we do find that countries differ in the extent of this vocational penalty, this disadvantage is not systematically related to the vocationality of the educational system. Our results, therefore, provide important insights into the question if adopting a dual system that combines vocational training and work is beneficial for individual workers in a country.

\section{Individual Life Cycle Effects of Vocational Training}

Although vocational education can take many forms, it is commonly distinguished from general education by the type of skills that are provided. Whereas in a general 
educational program students obtain mainly general skills (e.g., analytical thinking, literacy), vocational education equips students with highly occupation-specific skills (e.g., roofing, plumbing). Vocational education can either be school-based or be offered in a dual system in which students obtain their degree in an apprenticeship that combines school and work. Vocational education is commonly seen as advantageous for labor market allocation (Shavit and Müller 1998; Müller and Gangl 2003; Breen 2005). Numerous studies show that individuals with a vocational qualification find a job faster (e.g., Wolbers 2007; Wolter and Ryan 2011) and have a lower probability of being unemployed at the start of their career (e.g., Ryan 2001). The main explanation for these positive effects is that the occupation- and sometimes even firm-specific skills that students obtain in vocational programs make them directly productive in the labor market and thereby attractive to employers (Arum and Shavit 1995; Scherer 2005; Van de Werfhorst 2011).

Although Hanushek et al. (2016) underscore this early career advantage, they point to a potential trade-off with the labor market returns to a vocational qualification at the end of the career. They argue that technological innovation has changed-and is still changing - the skills that are demanded in the labor market. Indeed, this is what several studies, both in sociology and economics, find when looking at the past fifty years (Katz and Murphy 1992; Liu and Grusky 2013; Autor and Dorn 2013). According to Hanushek and colleagues, the consequences of these technological changes are more severe for vocationally trained workers who have an (occupation-) specific skill set that is likely to become obsolete as the job content changes than for those with a general qualification who are more flexible and better able to respond to changes in skill demands.

The effect of vocational education on employment is, therefore, argued to change over the life cycle. At first, vocationally schooled individuals are attractive because they have the right skill-set and are immediately productive. When they are older, it is more likely that their skills will be outdated, making them less attractive to employers. This inflexibility of having a vocational skill set especially becomes a burden for vocationally schooled workers that are laid off and have to look for a new job at a later age.

Empirical support for this hypothesis is scarce, with the exception of Hanushek et al. (2016). Using data on 11 countries from the International Adult Literacy Survey (IALS), the authors report that at an age of 16, vocational graduates are about 7 percentage points more likely to be employed than individuals with general education, but that this gap narrows and subsequently reverses into a disadvantage after the age of 50. Hanushek and colleagues also look at the relation between vocational education and wage returns, but these results are much less convincing and only partially support their hypotheses. For this reason, we focus on their main finding and only study the effect of vocational education on employment. ${ }^{1}$

An important question is whether the changing returns to a vocational qualification over the life cycle should be explained as an age effect or a cohort effect. The proposed explanations clearly hint at an interaction between the two: at a later age, skills become more outdated, but this pattern is especially strong when, over time, technological change affected the skills that are demanded from different cohorts. Due to the limitations of cross-sectional data, it reaches beyond the scope of this 
study to investigate to what extent the disadvantage of having a vocational qualification in later life should be interpreted as an age or a cohort effect. ${ }^{2}$ We follow the design of Hanushek et al. (2016) and test our hypotheses in a cross-sectional design:

- H1a: Vocational education has a positive effect on the probability of being employed early in the career.

- H1b: The benefit of vocational education reverses into a penalty later in the life cycle.

\section{The Moderating Effect of the Educational System}

One of the most prominent dimensions on which national educational systems vary is the extent to which they provide students with (occupation-)specific skills (e.g., Bol and Van de Werfhorst 2013). There are different types of vocational systems, among which some provide vocational training in fully school-based programs, whereas others offer a combination of school and work in a so-called dual system (Ryan 2001). Comparative research has shown that the country-level setup of the vocational system matters for the labor market outcomes of school leavers. In countries where a high proportion of students obtain a vocational degree, labor market entry is smoother (Shavit and Müller 1998; Van der Velden and Wolbers 2003). Breen (2005) shows that both the specificity of skills and the strength of the link between schools and employers are beneficial for youth employment in vocational systems, and especially in dual systems.

Hanushek et al. (2016) argue that, for two reasons, the setup of the educational system is also important when studying changing effects of vocational training over the life cycle. First, students who are educated in a dual system will have the greatest benefits at the start of their careers. They have obtained highly occupationspecific-or even firm-specific - skills, more than in vocational systems that do not have dual training. At the same time, students in these systems are most vulnerable in their later career, when their highly specific skills become a strain. Students who have obtained their vocational education in a school-based system, on the other hand, will have more general skills than their equals in a dual system and will therefore suffer a smaller disadvantage in later life. Hanushek et al. (2016) state that in vocationally oriented countries, the processes of skill out-dating and a lack of flexibility are especially strong and affect a large proportion of workers.

A second reason why the vocational orientation of the educational system might affect the life cycle returns to a vocational degree is related to skill updating. More specifically, the level of adult training is lower for vocationally than for generally trained workers. Hanushek et al. (2016) argue that the absence of adult training for vocationally schooled workers is especially strong in systems that offer highly occupation-specific skills. Above all, in countries with an apprenticeship system, vocationally trained workers seem to receive less training than individuals with general training when they are older. In those systems, employers are used to hiring trained workers who are immediately ready to work and are not used to investing in skill updating. 
For these two reasons, the trade-off between early benefits and late disadvantages is expected to be larger in educational systems that offer highly occupationspecific vocational programs. Hanushek et al. (2016) find empirical support for this institutional-level hypothesis. After classifying countries as having a general or vocational education system and further differentiating the vocational systems in school-based, non-school-based, and apprenticeship systems, they find the strongest decline in the effect of vocational education on employment in the countries that offer apprenticeships in a dual system. Following these arguments, two hypotheses are formulated:

- H2a: The pattern of vocational decline is stronger in countries with high vocational enrollment compared to countries with a weak vocational sector.

- H2b: Vocational decline is strongest in countries with a high dual system enrollment.

In this article, we focus on the role of the educational system in mediating the effect of education on employment. However, it is well known that the structure of the labor market is also important for the transition into employment. It is a possibility that these labor market institutions interact with the employment probabilities of vocationally and generally trained workers in a different way in different countries. Educational systems and labor market institutions often evolve in tandem, as the Varieties of Capitalism approach emphasized (Estevez-Abe et al. 2001). Strong vocational sectors can only be maintained as an attractive option for students if employment conditions are rather generous and protection is high. Because such complex institutional complementarities can best be coordinated outside the market sphere, the combination of strong vocational (especially dual) education systems, employment protection, and generous pension systems is typical of coordinated, as opposed to liberal market economies. This means that we have to be somewhat cautious with regard to a causal interpretation of the moderating effect of vocational educational systems. Yet, it should be noted that coordination of employment relations as such is unlikely to offer an alternative explanation for a moderating effect of the vocational education sector, as there are multiple skill equilibria even within the category of coordinated market economies (Iversen and Stephens 2008). For instance, in Scandinavian countries, coordination has not resulted in a strong vocational sector, whereas in Germany and the Netherlands it has. In additional analyses, we do control for the influence of early retirement levels in the different countries, the factor that we believe is most likely to offer a competing explanation for a possible decline of employment opportunities of the vocationally qualified labor force in the later career. Including a measure for early retirement schemes into our analyses does not change the results. Therefore, our prime focus is on the hypothesis of Hanushek et al. (2016) that the life cycle effect of vocational education varies across educational systems. 


\section{Methods $^{3}$}

\section{Data}

We use data from the Programme for the International Assessment of Adult Competencies (PIAAC) from 2012 to investigate our hypotheses. This cross-national survey, administered in 24 OECD countries, consists of a sociodemographic background questionnaire and a battery of cognitive tests that assessed literacy, numeracy, and problem-solving. The analyses in this article include data for 22 countries. ${ }^{4}$

Our analytical sample only contains respondents that are not currently enrolled in education and have at least completed lower secondary education, given that in all countries only from that point onwards educational programs are differentiated in vocational and general programs. As it is well known that women's employment patterns are highly different from men's (which, in turn, also differs across countries), all analyses are carried out separately for male and female respondents. The final sample consists of 52,677 men and 57,955 women across the 22 countries.

The PIAAC data are complemented with two indicators that characterize educational systems in their level of vocational orientation (Bol and Van de Werfhorst 2013).

\section{Operationalization}

Descriptive statistics and descriptions of the coding of all variables are presented separately for men and women in Table $1 .^{5}$

The dependent variable is a dichotomous measure for employment status that differentiates between people who are currently employed and those who are not. All employment activities are counted no matter the weekly hours or other contract properties. Similar to Hanushek et al. (2016), we model employment instead of unemployment, acknowledging that vocational education can decrease employment in different ways. Reasons for not being employed include unemployment, as well as retirement and other forms of absence from the labor force. In our pooled sample, 81 percent of men are employed compared to 70 percent of women.

The main independent variables are age and type of education of the respondents. Education type measures if the highest educational degree is general or vocational/VET. Thereby, general degrees are those that do not involve vocational training in secondary education and those tertiary degrees that are conveyed by universities (in contrast to professional higher education institutions). General degrees are commonly classified as type A in the International Standard Classification of Education (ISCED). ${ }^{6}$ In the sample, 39 percent of men and 38 percent of women left the formal education system with a vocational degree. The impact of vocational education at different stages of the life cycle is investigated by looking at respondents of different age. ${ }^{7}$ A quadratic term of age is added to the analyses as numerous studies have shown that the effect of age on employment is curvilinear and decreases as individuals come closer to retirement. The average age in the sample is about 43 years for both men and women, with age ranging from 16 to 65 .

A number of control variables is included to account for selection into the two different types of education. The most important control is for people's cognitive 
Table 1: Summary Statistics and Coding of Variables

\begin{tabular}{|c|c|c|c|c|c|c|c|c|}
\hline \multirow[t]{2}{*}{ Variable } & \multicolumn{3}{|c|}{ Men } & \multicolumn{3}{|c|}{ Women } & \multirow[t]{2}{*}{ Range } & \multirow[t]{2}{*}{ Description } \\
\hline & mean & $\mathrm{sd}$ & $\mathrm{N}$ & mean & $\mathrm{sd}$ & $\mathrm{N}$ & & \\
\hline Employed & 0.81 & 0.39 & 52,677 & 0.70 & 0.45 & 57,955 & $0-1$ & $\begin{array}{l}\text { Dichotomous variable of } \\
\text { current employment, with } \\
\text { not-employed as reference } \\
\text { category. }\end{array}$ \\
\hline Age & 42.96 & 12.41 & 52,677 & 43.46 & 12.33 & 57,955 & $16-65$ & $\begin{array}{l}\text { Continuous measure of age of } \\
\text { respondent. In all analyses } \\
\text { age is recoded so that the } \\
\text { minimum age of } 16 \text { receives } \\
\text { the value 0, which leads } \\
\text { to more meaningful inter- } \\
\text { cepts for the interaction effects. }\end{array}$ \\
\hline $\begin{array}{l}\text { Type of } \\
\text { Education } \\
\text { (VET) }\end{array}$ & 0.39 & 0.46 & 52,677 & 0.38 & 0.46 & 57,955 & $0-1$ & $\begin{array}{l}\text { Dichotomous variable with } \\
\text { general education as reference } \\
\text { category. }\end{array}$ \\
\hline Numeracy & 2.77 & 0.49 & 52,677 & 2.66 & 0.47 & 57,955 & $0.40-4.56$ & $\begin{array}{l}\text { Numeracy score in the PIAAC } \\
\text { skills test. The test score for } \\
\text { skills is divided by } 100 \text { for the } \\
\text { analyses to make coefficients } \\
\text { better readable. PIAAC uses } \\
\text { plausible values for test scores. } \\
\text { Multiple imputation in all } \\
\text { analyses accounts for } \\
\text { this data property. }\end{array}$ \\
\hline $\begin{array}{l}\text { Level of } \\
\text { Education }\end{array}$ & 2.19 & 0.66 & 52,677 & 2.22 & 0.68 & 57,955 & $1-3$ & $\begin{array}{l}\text { Education of respondent } \\
\text { on three levels: lower } \\
\text { secondary education (1), } \\
\text { upper secondary or post- } \\
\text { secondary education (2), } \\
\text { and tertiary education (3). }\end{array}$ \\
\hline $\begin{array}{l}\text { Parental } \\
\text { Education }\end{array}$ & 1.86 & 0.72 & 52,677 & 1.84 & 0.72 & 57,955 & $1-3$ & $\begin{array}{l}\text { Highest education of both } \\
\text { parents combined on three } \\
\text { levels: primary education or } \\
\text { less (1), secondary education } \\
\text { (2), and higher education (3). }\end{array}$ \\
\hline
\end{tabular}

Source: PIAAC 2012, release March 2015, own calculations. 
skills. Individuals who are less competent select themselves more often into vocational rather than general education (Arum and Shavit 1995). Controlling for competencies is therefore highly important to obtain good estimates of the effect of vocational education on employment. PIAAC includes competency measures for three different but closely related domains: numeracy, literacy, and problem-solving. In line with other studies, we use numeracy (e.g., Levels et al. 2014). ${ }^{8}$ The OECD (2013) defines numeracy as the ability to use, apply, interpret, and communicate mathematical information and ideas. To assess individuals' numeracy, 52 items were used in an adaptive test. Because of time constraints, respondents only answered a random number of items. As a consequence of this, the final score on the numeracy test is included in the data as ten plausible values that need to be analyzed using imputation methods (see section on the empirical strategy). The mean numeracy value is 2.77 for men and 2.66 for women. Next to numeracy, we control for parents' education, as social background has been found to have a strong influence on educational trajectories. Just as with numeracy, we need to control for this selection into types of education if we want to estimate the effect of vocational education. Finally, we include the educational level of respondents in our models, as the distribution of vocational and general degrees is different between educational levels. We thus look at the within-level effects of having a vocational degree.

To assess whether educational systems moderate the relationship between age, vocational education, and employment, two indicators are used. The first indicator (vocational enrollment) measures the size of the vocational education system in a country. It reflects the share of students that is enrolled in vocational in contrast to academic tracks. Using two different sources for the proportion of vocational enrollment in upper secondary education, Bol and Van de Werfhorst (2013) generate a standardized index for the share of the vocational system in a country. This measure ranges from -1.84 in the United States to 1.74 in the Czech Republic. The second indicator (dual system enrollment) measures the size of the dual system (Bol and Van de Werfhorst 2013). It is included as educational systems differ not only in the sheer size of the vocational sector (as measured by the vocational enrollment indicator), but also in the specificity of the skills they provide. For this reason, the second variable measures the size of the dual system as a percentage of vocational enrollment in programs in which work and school are combined. Enrollment in the dual system is highest in Denmark with 48 percent and lowest in a number of countries in which no dual system exists (Canada, Italy, Japan, Korea, Sweden, United Kingdom, United States). ${ }^{9}$ Both variables display different aspects of the vocational orientation of an educational system that are deemed to be important by earlier studies (Bol and Van de Werfhorst 2013; Breen 2005; Hanushek et al. 2016). Vocational enrollment gives a broad indication of participation in vocational programs independent of the actual skill specificity, whereas dual system enrollment is a more direct indicator of the specificity of skills conveyed by vocational education. The variation of the two indicators for the countries is shown in Figure 1. For obvious reasons, the two indicators are correlated, but at the same time we see important differences between them. 


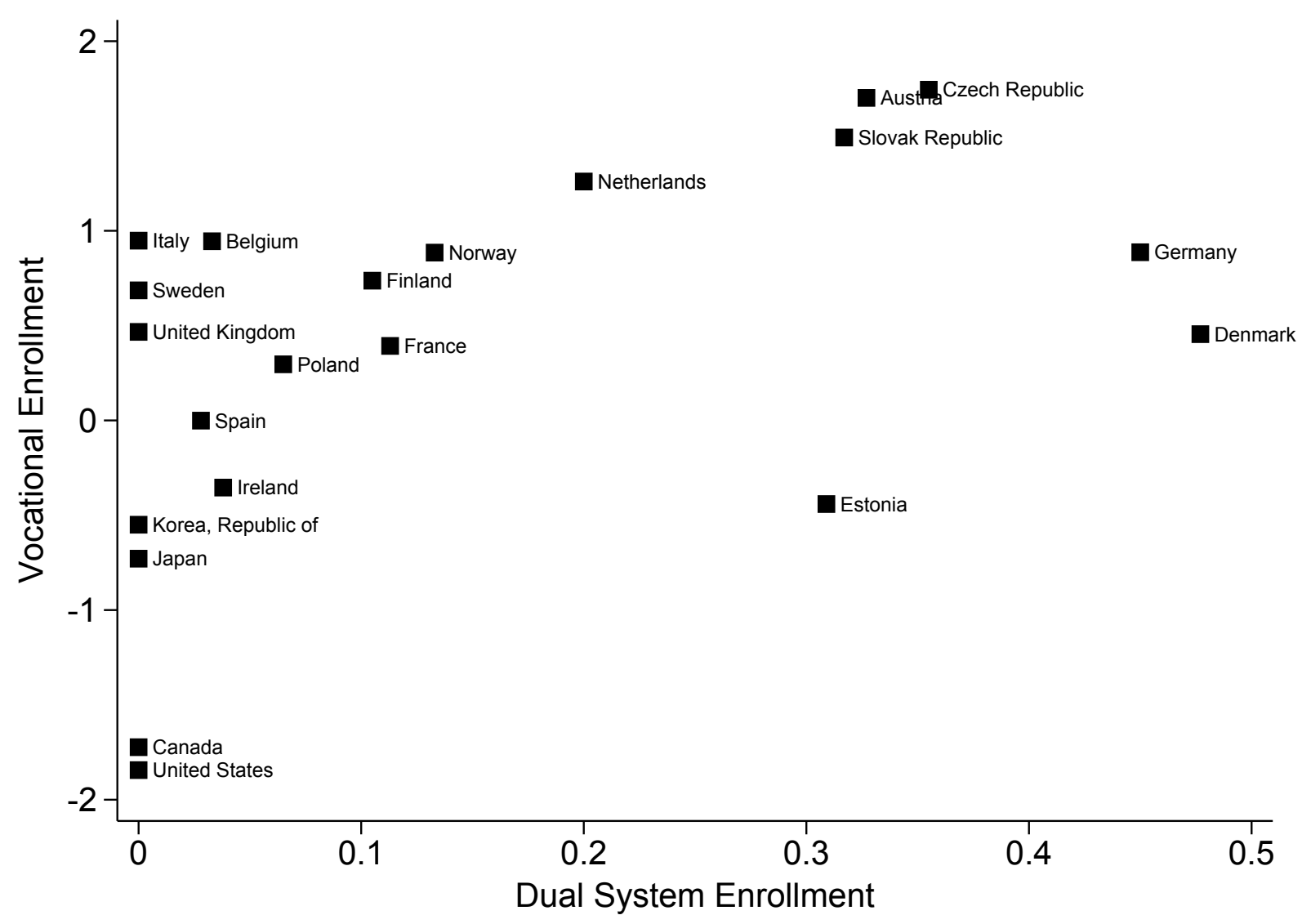

Figure 1: Correlation of the two country-level indicators vocational enrollment and dual system enrollment.

Source: Bol and Van de Werfhorst (2013), version 4, own calculations.

\section{Empirical Strategy}

As we model a binary dependent variable, we use logistic regression models. Linear probability models are also explored, but given that a substantial part of our results are interpreted using predicted probabilities, we decided to show the results for the logistic regression models. No substantial differences are found when we use linear probability models.

As we are interested in how the effect of vocational education changes over the life cycle, our primary focus is on the interaction effect between age and type of education (vocational vs. general) on the employment probability. ${ }^{10}$ A negative interaction effect indicates that the predicted probability of being employed decreases with age for people with vocational education and would confirm the hypothesis of vocational life cycle decline.

In all our analyses we use country fixed effects to account for all relevant country differences. Because we include country fixed effects, we are not able to estimate the main effects of our two country-level variables (vocational enrollment and dual 
system enrollment). For our analyses this is not a problem, as we are only interested in the moderating effect of the two country level variables. These can be estimated irrespective of the country-level main effects. For a similar approach, see Bol et al. 2014. Three sets of analyses are carried out:

1. A pooled analysis with country fixed effects is implemented to show the average individual-level effect of the interaction of age and VET on employment across countries. The results of the pooled regression are displayed in Table 2 and Figure 2.

2. The influence of the country-level educational system indicators on the individual-level relationship between age, VET, and employment is tested formally by adding a three-way-interaction for age $\times$ VET $\times$ Vocational Enrollment/Dual System Enrollment to the fixed effects models. The results are presented in Table 3 and Figures 3 and 4.

3. Separate regression models are calculated for all countries. The results are displayed in Figure 5 for men. The results for women as well as the full regression tables for both genders can be found in the online supplement.

In all of our analyses, we use the sampling weights that are provided by the PIAAC survey, scaled in such a way that each country contributes equally to the analyses. As we have mentioned before, numeracy is included as a set of ten plausible values. To include numeracy as a control, we rely on multiple imputation models in which the (plausible) values for numeracy are analyzed as ten imputations of the true (but unobserved) result of a respondent on the full numeracy test (cf. Rubin 1976). Please note that we do not impute any other variables, given the low number of missings on our key variables.

\section{Results}

\section{Effects of Vocational Education over the Life Cycle}

First, we carry out a pooled regression with country fixed effects to evaluate the individual-level hypothesis that having a vocational education degree results in higher employment probabilities at the start of the career, but lower employment probabilities at the end of the career. The results are shown in Table 2.

Model 1 contains the main variables of interest: age, vocational education (VET), and all control variables besides numeracy. Age has a positive and significant influence on employment probabilities for men and women. The negative and significant squared age term shows that this effect is curvilinear: young and old people are least likely to be employed. The coefficient for VET is negative and significant for both men and women. A vocational degree leads to lower employment probabilities than a general degree. This effect of VET is the average effect of being vocationally educated across the life cycle.

In model 2, we add the interaction between VET and age. The main effect of age remains positive and again shows a curvilinear pattern. The main effect of VET is now positive and significant for men and women. For 16-year-old men, our 
Table 2: Pooled Logistic Regression Models with Country Fixed Effects and Employment as Dependent Variable

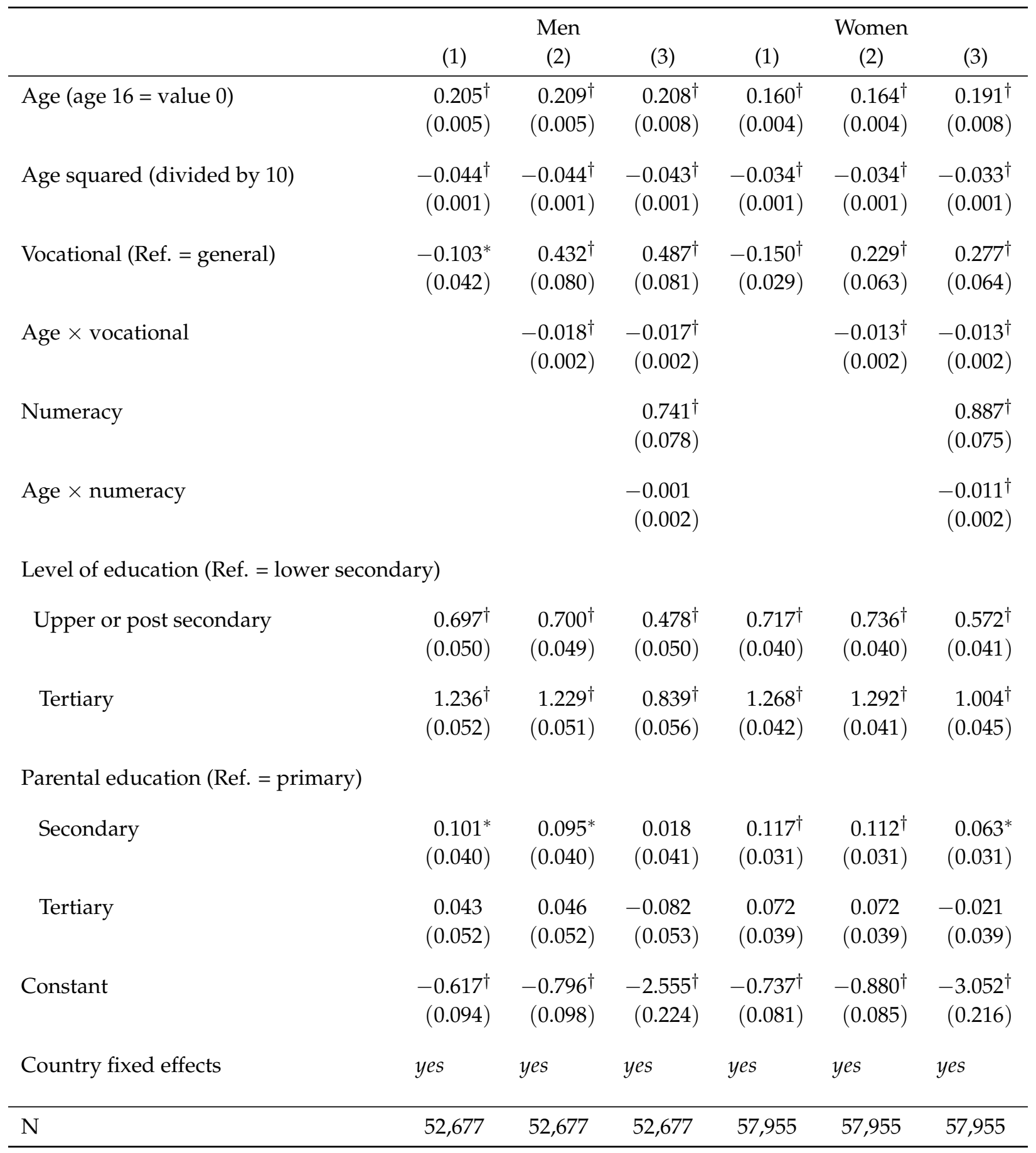

Note: Coefficients are logged odds. Standard errors in parentheses. Age squared is divided by 10 to improve the readability of coefficient and standard error. $* \mathrm{p}<0.05 ; \dagger \mathrm{p}<0.01$

Source: PIAAC 2012, release March 2015, own calculations 
model predicts that a vocational degree multiplies the odds of being employed by $e^{0.432}=1.54$. For women, we find a somewhat smaller main effect $\left(e^{0.229}=1.26\right)$. This confirms Hypothesis H1a: vocational education has a positive effect on being employed at the start of the career. However, the main interest of this study is the interaction between age and VET. The interaction effect is negative and significant for both genders. With increasing age, the positive effect of VET decreases and reverses into a negative effect at a higher age. This confirms Hypothesis H1b: on the individual level, the effect of vocational education on employment changes over the life cycle, eventually reversing the probability of employment to the favor of general education later in the career.

In model 3, numeracy is added as a further control for selection into type of education. We also add the interaction between numeracy and age to account for shifts in the skill level of the population across different cohorts (Hanushek et al. 2016). We find a strong effect of numeracy on employment. For women, we find that with increasing age, the skill level becomes less important for employment probabilities, whereas for men there is no such change. Most important is, however, that the interaction between vocational education and age is unaffected by adding numeracy as a control: when individuals get older, the effect of vocational education decreases and eventually becomes negative.

To assess the vocational decline pattern in more detail, Figure 2 shows predicted probabilities of being employed for the two educational groups across the life cycle separately for men (a) and women (b). The figure makes clear that the initial benefit of having a vocational degree (dashed blue line) over having a general degree (solid red line) decreases and reverses eventually. For men, the age at which we predict that workers with general education surpass those with vocational education is at 45 , whereas for women it is at $36 .{ }^{11}$ Although the difference only becomes significant at a later point, the results provide clear support for Hypothesis 1a: the employment premium associated with a vocational degree in the early career turns into a penalty later in the career.

\section{The Moderating Effect of the Educational System}

In the next series of models, we test whether the extent to which the VET effect changes over the life cycle depends on the setup of the educational system. Technically, this means that we add interactions with the country-level indicators to our fixed effects models to investigate a three-way interaction between age, VET, and the vocationality of the education system (measured by the vocational enrollment and dual system enrollment indicators). The results of these analyses for the samples of men and women with both country-level predictors are presented in Table 3.

The upper panel of the table shows the three-way interaction with the vocational enrollment indicator. If Hanushek et al. (2016) are right, we should observe a negative three-way interaction, meaning that the decrease in the effect of vocational education on employment over the life cycle is strongest in countries with a more vocationally oriented educational system. Our models predict very small and non-significant effects for the three-way interactions both for men and for women. 


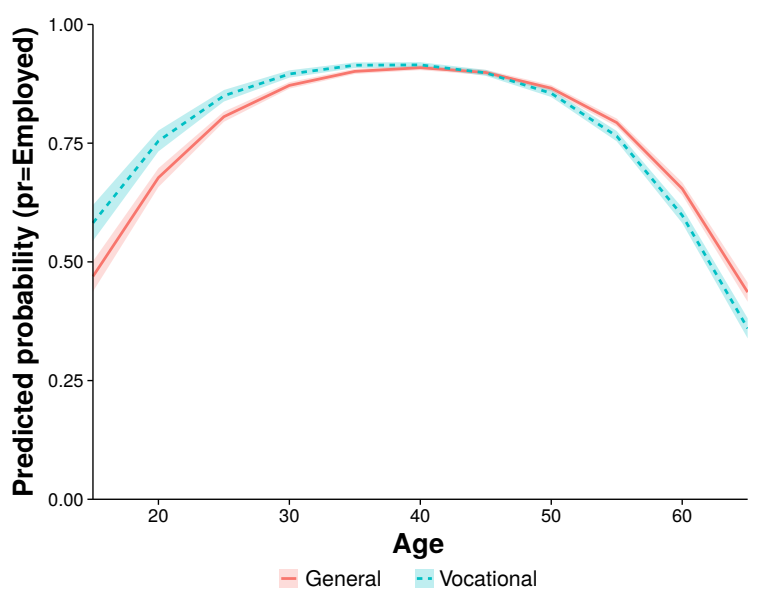

(a) Men

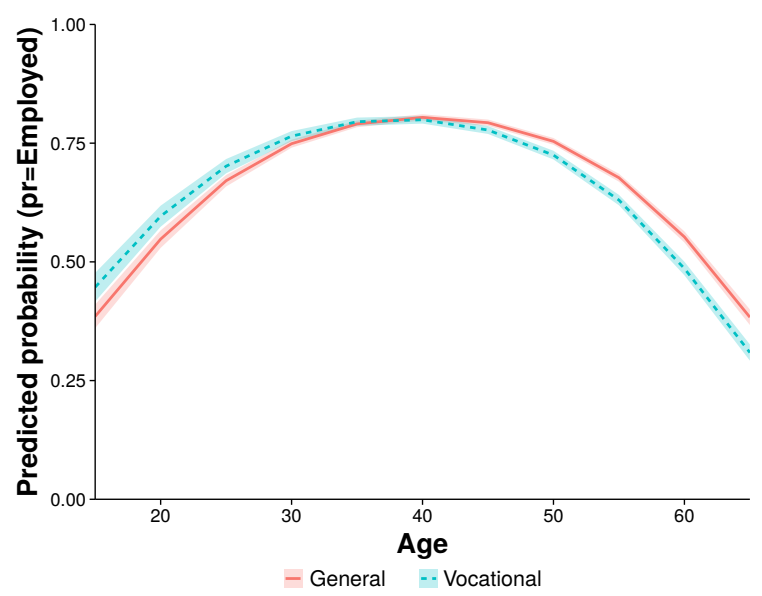

(b) Women

Figure 2: Predicted probabilities of employment by type of education (vocational/general).

Note: The estimates of the predicted probabilities are based on model 3 with the full set of predictors. All variables besides the dummy for vocational education are set at their means for this prediction. Age is used in its original form with years of age corresponding to values of the variable. Source: PIAAC 2012, release March 2015, own calculations.

We find no evidence that the life cycle effect of vocational education differs systematically across countries with a different vocational system and, hereby, refute Hypothesis H2a. There is a significant interaction between vocational enrollment and age, indicating that the likelihood of being employed is lower for (both vocationally and generally educated) older workers in countries where the vocational system is larger. ${ }^{12}$

The bottom panel of Table 3 shows the same interaction effects with dual system enrollment, indicating the extent to which the vocational system provides occupation-specific skills. Remember that the main argument is that vocational education leads to a higher penalty when the educational system provides more specific skills, making these workers less flexible in later life. Again, we find only a very small and insignificant effect for the three-way interaction, indicating that there is no systematic difference in the age $\times$ VET interaction across systems that differ in the specificity of the skills they teach in their vocational programs. Thereby, we also refute Hypothesis $2 \mathrm{~b}$ : the extent to which the effect of vocational education decreases over the life cycle is not higher if a country's educational system offers more occupation-specific skills.

To illustrate these results, we look at the average marginal effect of vocational education on employment changes over the life cycle in countries that score differently on the vocational enrollment indicator (Figure 3) and the dual system enrollment indicator (Figure 4). The figures are again separate for men (a) and women (b).

In Figure 3, the dashed blue lines represent countries with a large vocational education system (vocational enrollment $=1.5$ ). Countries with small vocational education system (vocational enrollment $=-1.5$ ) are represented by the solid red lines. The average marginal effect of having a vocational degree (compared to a 
Table 3: Three-Way Interaction Logistic Regression Models with Country-Level Indicators and Employment as Dependent Variable (Selected Coefficients)

\begin{tabular}{|c|c|c|}
\hline & Men & Women \\
\hline Age (age $16=$ value 0 ) & $\begin{array}{c}0.206^{\dagger} \\
(0.008)\end{array}$ & $\begin{array}{c}0.189^{\dagger} \\
(0.008)\end{array}$ \\
\hline Age squared (divided by 10) & $\begin{array}{r}-0.043^{\dagger} \\
(0.001)\end{array}$ & $\begin{array}{r}-0.033^{\dagger} \\
(0.001)\end{array}$ \\
\hline VET (Ref. = general) & $\begin{array}{r}0.383^{\dagger} \\
(0.084)\end{array}$ & $\begin{array}{c}0.246^{\dagger} \\
(0.065)\end{array}$ \\
\hline Age $\times$ vocational enrollment & $\begin{array}{r}-0.004^{\dagger} \\
(0.001)\end{array}$ & $\begin{array}{r}-0.004^{\dagger} \\
(0.001)\end{array}$ \\
\hline VET $\times$ vocational enrollment & $\begin{array}{c}0.161^{*} \\
(0.076)\end{array}$ & $\begin{array}{c}0.049 \\
(0.066)\end{array}$ \\
\hline VET $\times$ age $\times$ vocational enrollment & $\begin{array}{r}-0.003 \\
(0.002)\end{array}$ & $\begin{array}{c}-0.001 \\
(0.002)\end{array}$ \\
\hline $\mathrm{N}$ & 52,677 & 57,955 \\
\hline Age (age $16=$ value 0$)$ & $\begin{array}{r}0.207^{\dagger} \\
(0.008)\end{array}$ & $\begin{array}{c}0.191^{\dagger} \\
(0.008)\end{array}$ \\
\hline Age squared (divided by 10) & $\begin{array}{r}-0.043^{\dagger} \\
(0.001)\end{array}$ & $\begin{array}{r}-0.033^{\dagger} \\
(0.001)\end{array}$ \\
\hline VET (Ref. = general) & $\begin{array}{c}0.250^{*} \\
(0.110)\end{array}$ & $\begin{array}{c}0.159 \\
(0.086)\end{array}$ \\
\hline Age $\times$ dual system enrollment & $\begin{array}{c}-0.012 \\
(0.009)\end{array}$ & $\begin{array}{r}-0.004 \\
(0.008)\end{array}$ \\
\hline VET $\times$ dual system enrollment & $\begin{array}{r}1.384^{\dagger} \\
(0.504)\end{array}$ & $\begin{array}{r}1.047^{*} \\
(0.426)\end{array}$ \\
\hline VET $\times$ age $\times$ dual system enrollment & $\begin{array}{r}-0.022 \\
(0.014)\end{array}$ & $\begin{array}{c}-0.011 \\
(0.012)\end{array}$ \\
\hline $\mathrm{N}$ & 51,787 & 56,138 \\
\hline
\end{tabular}

Note: Coefficients are logged odds. Standard errors in parentheses. Age squared is divided by 10 to improve the readability of coefficient and standard error. These models also fit the effects of numeracy, the interaction between numeracy and age, country fixed effects, parental education, and level of education. For reasons of clarity, we do not display these effects. The dual system indicator is missing for Russia, which leads to the smaller sample size in the bottom panel of the table.

$* \mathrm{p}<0.05 ; \dagger \mathrm{p}<0.01$

Source: PIAAC 2012, release March 2015, own calculations. 


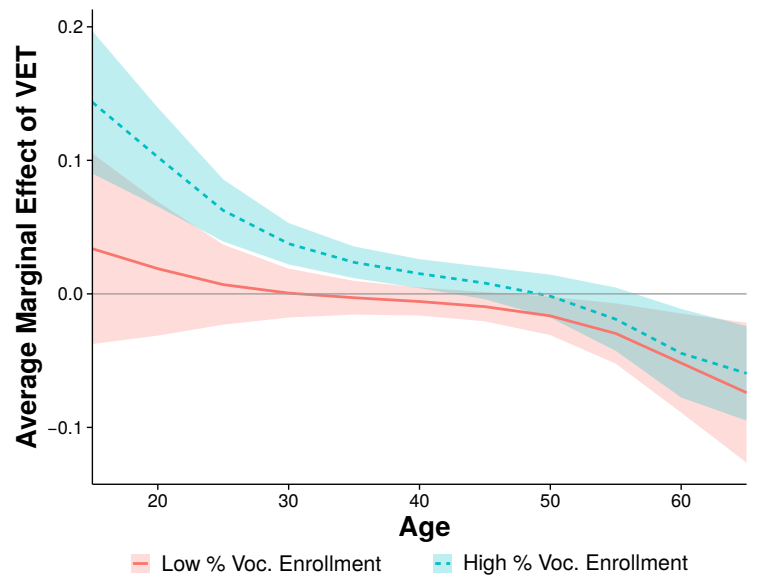

(a) Men

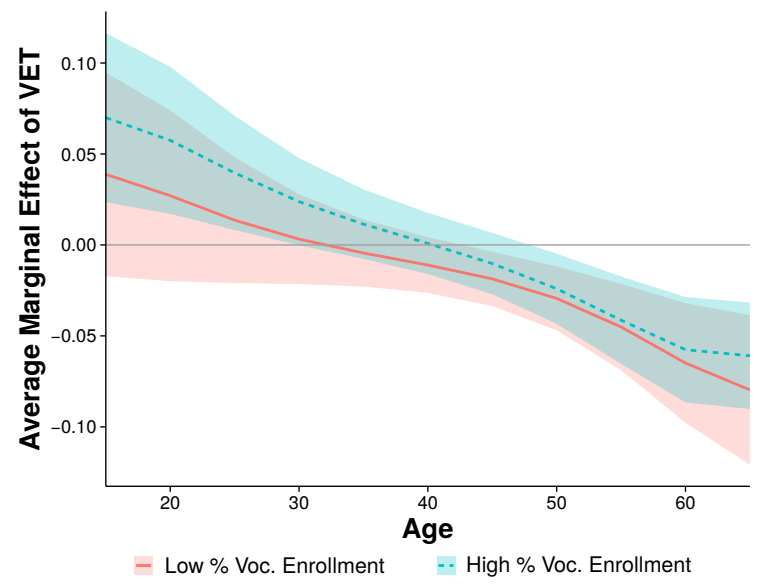

(b) Women

Figure 3: Average marginal effect of VET on employment in countries with low and high vocational enrollment.

Note: These graphs are based on the full model presented in Table 3. For the figures, age is used in its original form with years of age corresponding to values of the variable. Source: PIAAC 2012, release March 2015, own calculations.

general degree) is shown on the y-axis. For both genders, we find that a vocational degree has a positive effect on employment at the start of the career. This effect of having a VET degree is stronger in countries with an educational system that has a high percentage of students enrolled in vocational education. Towards the end of the career, the effect of having a vocational degree is highly similar for non-vocational and vocational systems. Vocationally educated are less likely to be employed, but not more so in countries with a strong vocational system. Overall, the life cycle patterns of vocational education are very similar in both types of countries.

In Figure 4, the same relationships are shown, now with the size of the dual system as country-level indicator. In the early career, vocationally educated are clearly better off in countries with a large dual system. In line with previous work, we find that dual systems are effective in increasing employment opportunities for school leavers (cf. Breen, 2005). In combination with our results from the pooled regressions, we see that the effect of vocational education on employment decreases and eventually becomes negative. However, the decline in the marginal effect of vocational education is very similar in both types of countries. If anything, being an older worker with a vocational degree seems less problematic in countries with a strong dual system-completely the opposite of what Hanushek et al. (2016) argued.

\section{Separate Country Analyses}

The previous analysis showed that countries do not vary systematically in the extent to which the effect of vocational education on employment decreases over the life cycle. A valid critique that one can have on the formal three-way interaction models 


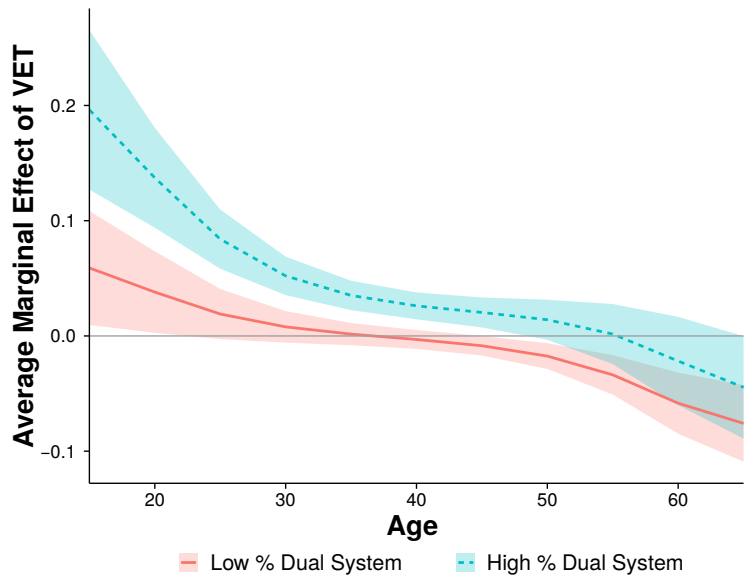

(a) Men

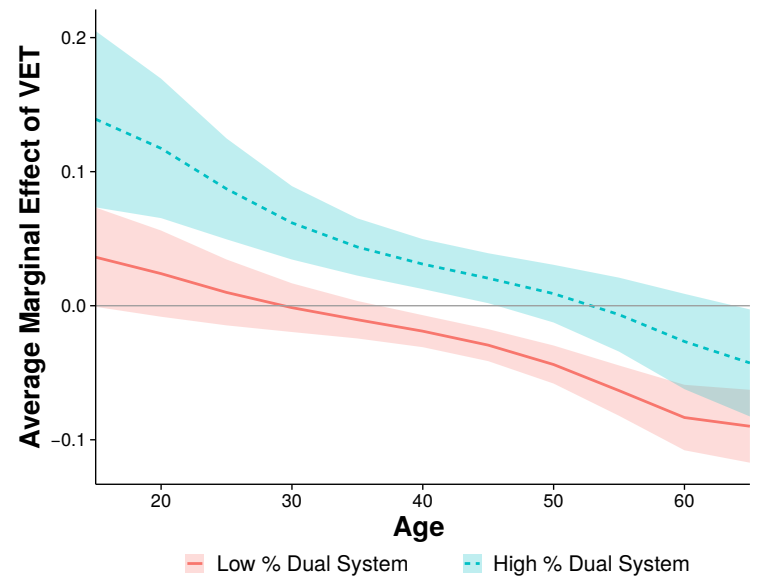

(b) Women

Figure 4: Average marginal effect of VET on employment in countries with low and high dual system enrollment.

Note: These graphs are based on the full model presented in Table 3. For the figures, age is used in its original form with years of age corresponding to values of the variable. Source: PIAAC 2012, release March 2015, own calculations.

is that they blur potential relevant differences between cases with a strong vocational system (Germany, Austria) and countries with a weak vocational system (United States, Canada). To explore these differences in more detail, we calculate logistic regressions for each country separately. Due to space constraints, we decided to only discuss the predicted probabilities figures for men (Figure 5). The results for women are highly similar and can be found in Figure B1 in the online supplement. ${ }^{13}$

In Figure 5, we see that countries are highly different in the initial benefit of having a vocational degree. Especially in Germany, Japan, and the Netherlands, our analyses predict that having a vocational degree increases the probability of being employed at the start of the career. It is striking that in Belgium and Austria, both with a strong vocational system, we do not find a big initial advantage of having a vocational degree. In most countries, we find that by the end of the career those with a general degree have a higher employment probability, although several countries seem to show more of a convergence between the predicted probabilities of both degrees. For a few countries, we find that being vocationally educated remains beneficial over the whole career, most clearly for students educated in the strongly vocational systems of the Netherlands and the Czech Republic. Some countries with a strong vocational system seem to corroborate Hypothesis 2a: Austria, Germany, and Denmark show the expected reversal of the advantage of a VET degree into a disadvantage. However, other countries with strong vocational system do not show such a pattern (Czech Republic, Slovakia, the Netherlands) and refute Hypothesis 2a. The same mixed pattern is visible for countries with weak vocational systems, of which some show vocational decline (Japan, United States) while others do not. If we compare the United States to Germany, two cases often pitted against each other in debates on educational reforms, we find a surprisingly similar interaction 

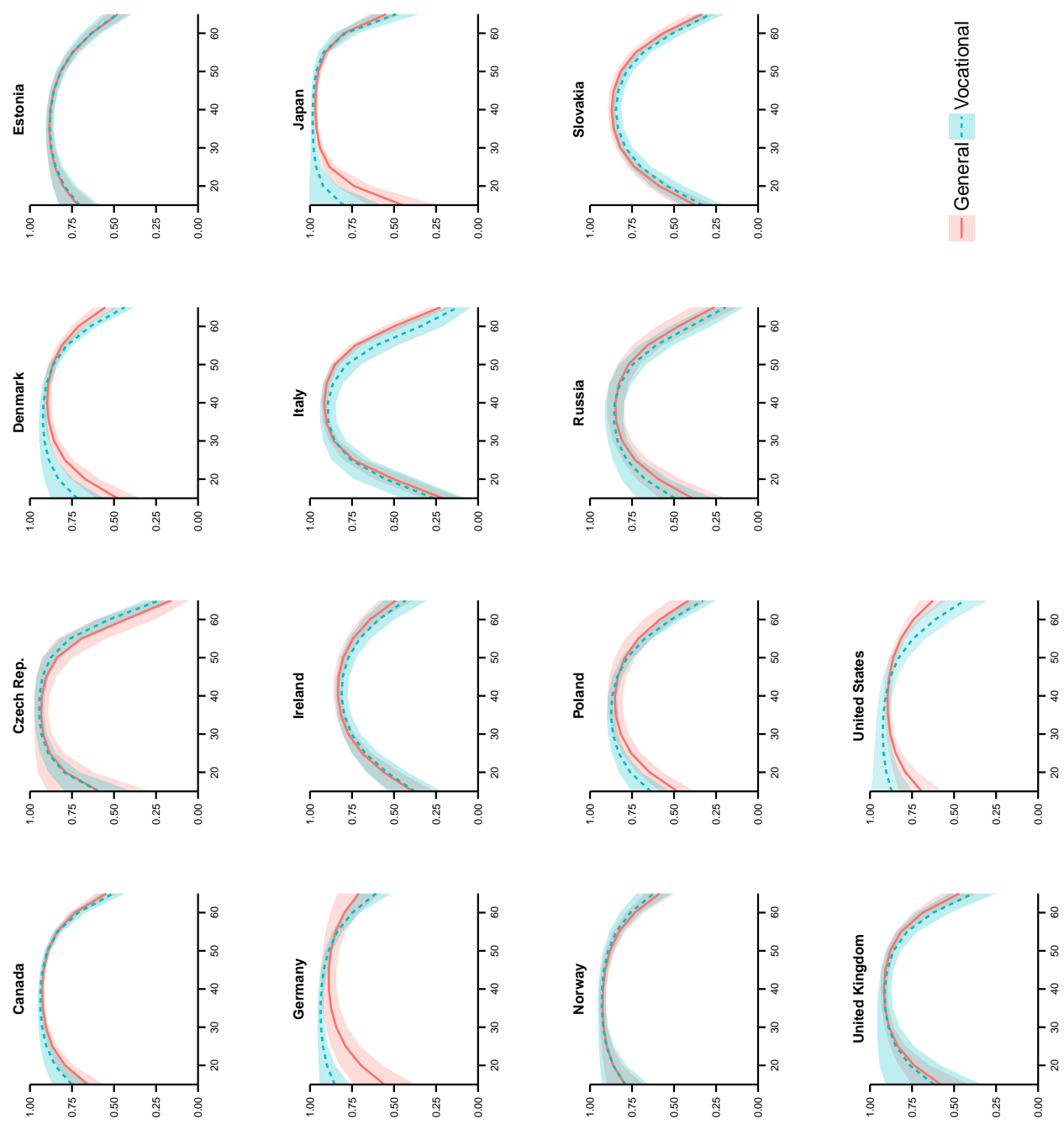

遮
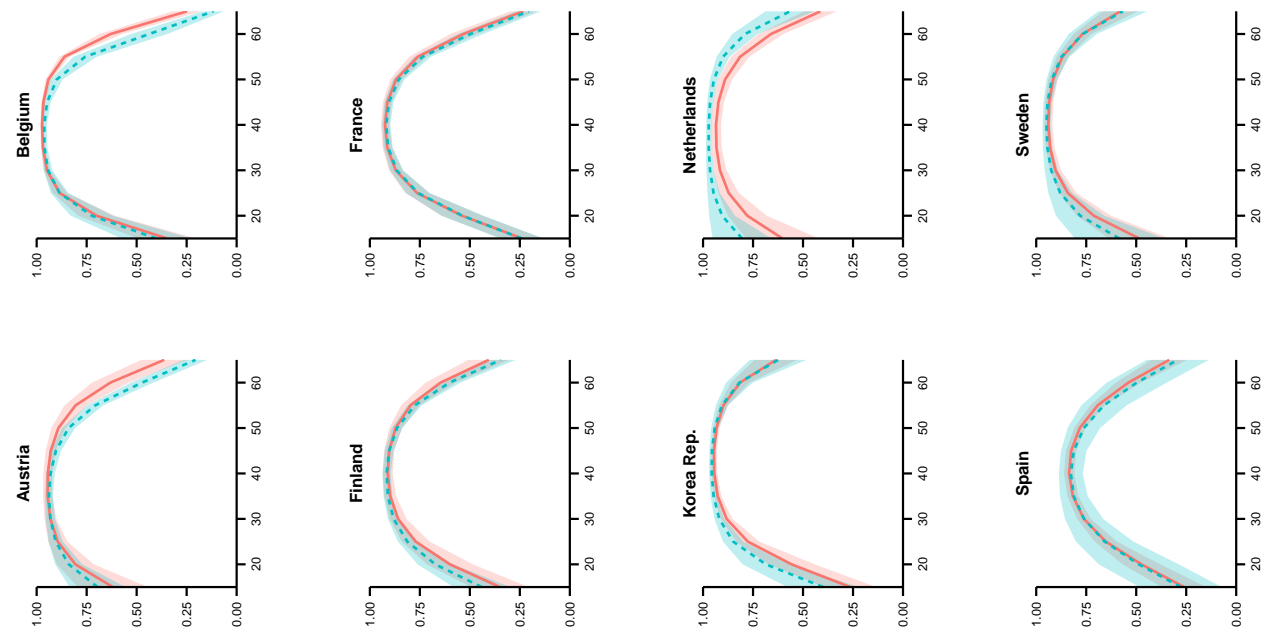

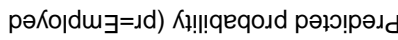

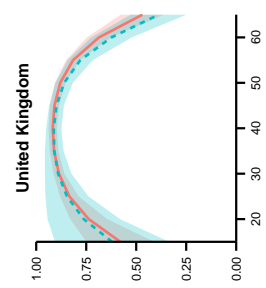

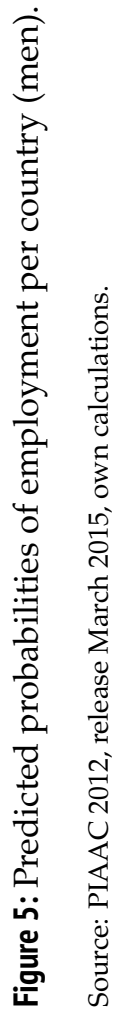


pattern. Although being vocationally educated clearly means something different in the dual system of Germany than it does in the United States, according to our analyses, this does not lead to different employment effects of having a VET degree.

The results of both the formal test of the three-way interaction and the separate country regressions provide convincing evidence that refutes the system-level hypothesis of Hanushek et al. (2016).

\section{Discussion}

Our analyses revealed that employment probabilities vary significantly between people educated in vocational and general academic forms of education. Our interest was particularly in life cycle developments in these educational cleavages. Although comparative stratification sociologists have since long demonstrated that vocational qualifications help to integrate young adults into the labor market, a pressing question is whether a potential advantage of vocational qualifications early in the career is off-set by disadvantages later in the life cycle. We indeed found such a pattern: people with a vocational qualification are more likely to be employed in the first part of the career, but have lower odds of employment later on (relative to those with more academically oriented forms of education).

An influential article by Hanushek et al. (2016) suggests that the life cycle reversal of initial advantage into later-career disadvantage is most prominent in countries with a strong vocational education and training (VET) sector. However, the hypothesis that the gap between people educated in vocational and general education across the life cycle is systematically related to a strongly institutionalized VET sector had not been formally tested. Our results did not confirm this hypothesis. Although the life cycle effects were indeed found, these were not typical for countries with a strongly developed VET system. A later-life decline in labor market prospects of people in vocational programs seems independent of the strength of the vocational system. Clearly, in each society there are groups with a qualification that might indicate less human capital. Those are all at a disadvantage in the later career independent of how the educational system is organized.

The multi-level nature of the research problem, in which vocational qualifications were assumed to be particularly harmful for late-career workers in societies with a strongly developed VET system, is of utmost importance for academic and policy debates. Academically, the study of stratification between education groups in different institutional contexts helps us to understand how microlevel life cycle outcomes are shaped by institutions. The present findings demonstrate crossnational differences in the early-career advantage of vocational qualifications in line with the existing comparative literature, but we did not find institutional differences in life cycle developments. Educational institutional contexts are clearly more relevant to understand early-career differences between countries than developments across the working career.

Of course, there are limitations to our study. Similar to Hanushek et al. (2016), we have studied this problem using cross-sectional data and are, therefore, unable to separate age, period, and cohort effects. Future research can exploit (national) longitudinal data to separate different explanations as for why older people with 
a vocational qualification have a lower employment probability than people with a general educational degree. An important reason to study the life cycle effects of vocational education using cross-sectional data is that we were able to study the relation between age, vocational education, and employment in a countrycomparative perspective. It is especially at this system-level that policy claims concerning vocational education are being made. Furthermore, similar to Hanushek et al. (2016), we have only focused on the educational system in explaining crossnational differences, although it is obvious that other country characteristics (e.g., related to the labor market or early retirement schemes) are likely to affect how the effect of education on employment develops over the life cycle. Nevertheless, it is an important step to investigate the role of (vocational) educational systems.

From a policy perspective, a call for a stronger VET sector has been made in the United States, assuming it would alleviate the problems of labor market integration of school leavers without full college degrees (Hoffman 2011; Rosenbaum et al. 2015). If, however, such a system deteriorated later-life chances, such a call would be ill-suited to reduce inequalities in American society. Based on our findings, we are reluctant to believe that a strengthening of the VET sector would be detrimental for later-life inequalities among education groups. Our study shows that debates about vocational education should be more clearly unfolded in microlevel and macrolevel problems. Although at the microlevel, those with comparatively low levels of education have disadvantages in the later career, we do not see institutional effects that should caution policy makers on strengthening the vocational education and training system, for instance by improving employer involvement. This does not mean that all institutions are irrelevant for late career outcomes, but it is not the educational institutional structure that seems to be important.

\section{Notes}

1 In additional analyses, we did look at wage returns. These analyses showed that there is no interaction effect between the type of degree (vocational or general) and age on log hourly wages which means that vocational decline in wage patterns is not present in our data. These results are available upon request.

2 The only way to disentangle cohort from age effects is by using longitudinal data. We are not aware of any longitudinal data that are available for several countries and contain information on the competencies of respondents. These requirements are crucial, however, for testing our second hypothesis that focuses on cross-national differences, and for controlling for selection of individuals with different competencies into vocational or general educational programs. For these reasons we test our hypotheses using a cross-sectional dataset.

3 Replication files to reproduce all our analyses can be found in the online supplement of this article and on the authors' websites.

4 Australia and Cyprus did participate in the survey but did not make their results available for the harmonized data set which can be used for cross-country comparisons.

5 All descriptive statistics are obtained using the Stata module -piaacdes-, provided with the data set. 
6 Two PIAAC variables are combined for this purpose. If respondents have obtained a secondary or post-secondary degree as highest level of education according to the variable EDCAT6, they are classified as vocational if the variable VET indicates that their highest degree is vocational. If they have obtained a tertiary degree, EDCAT6 directly differentiates between professional degree (5B) which is classified as vocational and research degrees (5A) which are classified as general.

7 For Austria, Canada, Germany, and the United States, a continuous age variable is missing in the data. For these countries, midpoints were assigned to the available 5-year bands of age.

8 Adding literacy in our models does not change the results. In fact, the two variables are so strongly correlated that there is no main effect of literacy when including numeracy.

9 The dual system indicator is missing for Russia. All analyses with this country-level variable, therefore, include only 21 countries.

10 Following Hanushek et al. (2016), we do not include the interaction between age squared and having a vocational degree in our models. In supplementary models, we did include this interaction. The results of these models can be found in Appendix A.

11 This is calculated in the following way: $(0.487 / 0.017)+16=45$ for men and $(0.277 / 0.013)+$ $16=36$ for women.

12 One reason for this might be that countries with a strong vocational system also tend to have more generous early retirement schemes, which explains why older workers are less employed in these systems. In supplementary analyses, we included an indicator for early retirement levels in our models, but the results hardly changed. These results are available upon request.

13 The full regression tables for both genders can be found in Tables B1 and B2 in the online supplement.

\section{References}

Arum, R., and Y. Shavit (1995). Secondary Vocational Education and the Transition from School to Work. Sociology of Education 68 (3), 187-204. http://dx . doi .org/10. 2307/ 2112684

Autor, D,. and D. Dorn (2013). The growth of low-skill service jobs and the polarization of the US labor market. The American Economic Review 103 (5), 1553-1597. http: //dx.doi.org/10.1257/aer.103.5.1553

Biavaschi, C., W. Eichhorst, C. Giulietti, M. Kendzia, A. Muravyev, J. Pieters, N. RodriguezPlanas, R. Schmidl, and K. Zimmerman (2013). Youth Unemployment and Vocational Training. Background Paper for the World Development Report 2013. Technical report, Worldbank.

Bol, T., and H. G. Van de Werfhorst (2013). Educational Systems and the Trade-Off between Labor Market Allocation and Equality of Educational Opportunity. Comparative Education Review 57 (2), 285-308. http://dx.doi.org/10.1086/669122

Bol, T., J. Witschge, H. G. Van de Werfhorst, and J. Dronkers (2014). Curricular Tracking and Central Examinations: Counterbalancing the Impact of Social Background on Student Achievement in 36 Countries. Social Forces 92 (4), 1545-1572. http://dx. doi .org/10. $1093 /$ sf /sou003

Breen, R. (2005). Explaining Cross-national Variation in Youth Unemployment: Market and Institutional Factors. European Sociological Review 21 (2), 125-134. http: //dx. doi .org/ 10.1093/esr/jci008 
Estevez-Abe, M., T. Iversen, and D. Soskice (2001). Social Protection and the Formation of Skills: A Reinterpretation of the Welfare State. In Varieties of Capitalism. The Institutional Foundations of Comparative Advantage, pp. 145-183. New York: Oxford University Press. http://dx.doi.org/10.1093/0199247757.003.0004

Hanushek, E. A., G. Schwerdt, L. Woessmann, and L. Zhang (2016). General education, vocational education, and labor-market outcomes over the life-cycle. Journal of Human Resources, forthcoming.

Hoffman, N. (2011). Schooling in the Workplace: How Six of the World's Best Vocational Education Systems Prepare Young People for Jobs and Life. Cambridge, Mass.: Harvard Education Press.

Iannelli, C., and D. Raffe (2007). Vocational Upper-Secondary Education and the Transition from School. European Sociological Review 23 (1), 49-63. http://dx . doi .org/10.1093/ esr/jcl019

Iversen, T., and J. D. Stephens (2008). Partisan politics, the welfare state, and three worlds of human capital formation. Comparative political studies 41 (4-5), 600-637. http: //dx.doi.org/10.1177/0010414007313117

Katz, L. F., and K. M. Murphy (1992). Changes in Relative Wages, 1963 - 1987: Supply and Demand Factors. The Quarterly Journal of Economics 107 (1), 35-78. http://dx. doi . org/10.2307/2118323

Krueger, D., and K. B. Kumar (2004a). Skill-specific rather than general education: A reason for US-Europe growth differences? Journal of economic growth 9 (2), 167-207. http://dx.doi.org/10.1023/B: JOEG.0000031426.09886.bd

Krueger, D., and K. B. Kumar (2004b). US-Europe differences in technology-driven growth: quantifying the role of education. Journal of monetary economics 51 (1), 161-190. http: //dx.doi.org/10.1016/j.jmoneco.2003.07.005

Levels, M., R. Van der Velden, and J. Allen (2014). Educational mismatches and skills: New empirical tests of old hypotheses. Oxford Economic Papers 66 (4), 959-982 http: //dx.doi.org/10.1093/oep/gpu024

Liu, Y., and D. B. Grusky (2013). The Payoff to Skill in the Third Industrial Revolution. American Journal of Sociology 118 (5), 1330-1374.

Müller, W., and M. Gangl (2003). Transitions from Education to Work in Europe: The Integration of Youth into EU Labour Markets. Oxford: Oxford University Press. http: //dx.doi.org/10.1093/0199252475.001.0001

OECD (2013). Technical Report of the Survey of Adults Skills (PIAAC). Technical report, Organization for Economic Cooperation and Development.

Rosenbaum, J., C. Ahearn, K. Becker, and J. Rosenbaum (2015). The New Forgotten Half and Research Directions to Support Them. New York: WT Grant Foundation.

Rubin, D. B. (1976). Inference and missing data. Biometrika 63 (3), 581-592. http: //dx. doi. org/10.1093/biomet/63.3.581

Ryan, P. (2001). The school-to-work transition: a cross-national perspective. Journal of economic literature 39 (1), 34-92. http: //dx . doi .org/10.1257/jel .39.1.34

Scherer, S. (2005). Patterns of Labour Market Entry - Long Wait or Career Instability? An Empirical Comparison of Italy, Great Britain and West Germany. European Sociological Review 21 (5), 427-440. http://dx.doi.org/10.1093/esr/jci029

Shavit, Y., and W. Müller (1998). From School to Work. A Comparative Study of Educational Qualifications and Occupational Destinations. Oxford: Clarendon Press. 
Van de Werfhorst, H. G. (2011). Skill and Education Effects on Earnings in 18 Countries: The Role of National Educational Institutions. Social Science Research 40 (4), 1078-1090. http://dx.doi.org/10.1016/j.ssresearch.2011.03.004

Van der Velden, R., and M. Wolbers (2003). The Integration of Young People into the Labour Market: The Role of Training Systems and Labour Market Regulation. In Transitions from Education to Work in Europe: The Integration of Youth into EU Labour Markets, pp. 186-211. Oxford: Oxford University Press.

Wolbers, M. H. J. (2007). Patterns of Labour Market Entry: A Comparative Perspective on School-to-Work Transitions in 11 European Countries. Acta Sociologica 50 (3), 189-210. http://dx.doi.org/10.1177/0001699307080924

Wolter, S. C., and P. Ryan (2011). Apprenticeship. In Handbook of the Economics of Education (1 ed.), Volume 4, pp. 521-576. North Holland: Elsevier.

Acknowledgements: This research was supported by several grants awarded by the Netherlands Organization for Scientific Research (NWO): A Vici grant (number 453-14-017), a NWO/NRO-PROO grant Educational Systems and Functions of Education (number 411-10-920), and a NWO/NRO-ProBo grant The Future of Craftsmanship (number 40515-400)

Andrea G. Forster: Department of Sociology, University of Amsterdam. E-mail: a.g.forster@uva.nl.

Thijs Bol: Department of Sociology, University of Amsterdam.

E-mail: t.bol@uva.nl.

Herman G. van de Werfhorst: Department of Sociology, University of Amsterdam. E-mail: h.g.vandewerfhorst@uva.nl. 